Article

\title{
Agonistic Interactions between Littermates Reappear after Mixing Multiple Litters at Weaning in Pigs
}

\author{
Maja Prevolnik Povše *, Nikolina Mesarec, Janko Skok and Dejan Škorjanc
}

Department of Animal Science, Faculty of Agriculture and Life Sciences, University of Maribor, Pivola 10, 2311 Hoče, Slovenia; mesarec.nikolina@gmail.com (N.M.); janko.skok@um.si (J.S.); dejan.skorjanc@um.si (D.Š.)

* Correspondence: maja.prevolnik@um.si; Tel.: +386-2-320-90-56

Citation: Prevolnik Povše, M.;

Mesarec, N.; Skok, J.; Škorjanc, D. Agonistic Interactions between Littermates Reappear after Mixing Multiple Litters at Weaning in Pigs. Agriculture 2021, 11, 844. https:// doi.org/10.3390/agriculture11090844

Academic Editor: Eva Voslarova

Received: 11 August 2021

Accepted: 30 August 2021

Published: 1 September 2021

Publisher's Note: MDPI stays neutral with regard to jurisdictional claims in published maps and institutional affiliations.

Copyright: (c) 2021 by the authors. Licensee MDPI, Basel, Switzerland. This article is an open access article distributed under the terms and conditions of the Creative Commons Attribution (CC BY) license (https:/ / creativecommons.org/licenses/by/ $4.0 /)$.

\begin{abstract}
Weaning involves mixing of unfamiliar litters and is accompanied by an outbreak of aggression, which is usually attributed to between-litter (BL) interactions. In the present study, we thus focused on post-weaning agonism (fighting and mounting) between littermates (within-litter, WL). Two litters were weaned into two pens separated by an empty pen and connected by narrow passages that were opened $24 \mathrm{~h}$ after weaning. WL interactions accounted for $38 \%$ and $68 \%$ of all fights and mounts, respectively, during a 7-day experimental period. After the passages were opened, not only BL, but also WL interactions increased significantly (by 6- to 7-fold on the first day of mixing). WL fights then gradually decreased, while WL mounts continued to increase. During the experimental period, the proportion of both WL fights and mounts decreased. The majority of WL fights $(\approx 80 \%)$ and mounts $(\approx 65 \%)$ occurred in home pens. A significantly higher percentage of draws was found in WL fights (50\% of initiator wins and $41 \%$ of draws) compared to BL fights ( $80 \%$ of initiator wins and $11 \%$ of draws). Results also showed less asymmetry in the body weight of piglets involved in WL interactions. Mixing of litters at weaning was shown to involve not only intense interactions between unfamiliar piglets but also the recurrence of agonistic interactions between littermates, which is something we should keep in mind when pursuing the highest standards of weaner welfare.
\end{abstract}

Keywords: pig; weaning; within-litter interactions; fighting; mounting

\section{Introduction}

Weaning, as is commonly carried out in contemporary intensive pig production, is known to trigger an outburst of aggression. In this process, two or more unfamiliar litters are brought together in a new weaning pen, which causes nutritional, psychosocial, and environmental changes associated with production practices, such as diet change, separation from the mother, mixing of non-littermate piglets, relocation/transportation, and/or changed temperature and air quality parameters [1,2]. The outbreak of aggression that arises at (and after) weaning because of these interacting stressors is often intuitively attributed to the conflicts between individuals from different litters. Namely, each of the original litters has already established a dominance hierarchy during the lactation period [3], and after mixing, piglets strive to establish a new social order through agonistic interactions with members of a new group [4,5]. However, in addition to interactions between unfamiliar individuals, the changes related to weaning most likely break down the previously established dominance hierarchy within the litter and thus stimulate new interactions related to dominance position among littermates. These within-litter interactions are often neglected, and therefore, when weaning aggression is studied, no special attention is usually paid to the interactions between littermates. However, from an animal welfare perspective, it is important to obtain information also on the possible changes in the dynamics of interactions between littermates that result from mixing unfamiliar litters. In the present study, we therefore focused on the agonistic interactions within the original 
litter after weaning and mixing with another litter. The aim was to examine temporal and territorial dynamics and the outcome (win/lose/draw) of within-litter interactions versus between-litter interactions. We hypothesised that (i) within-litter interactions, both fighting and mounting, increase significantly after two litters are mixed and then gradually decrease after a few days of mixing, (ii) within-litter interactions occur predominantly in the pen in which the litter was weaned, (iii) a large proportion of within-litter fights end in a draw, and (iv) opponents in the within-litter interactions are less asymmetric in body weight, which serves as an indirect measure of the resource holding potential (RHP).

\section{Material and Methods}

\subsection{Animals and Housing}

The study was carried out at the Pig Research Centre, Faculty of Agriculture and Life Sciences (University of Maribor), in a period of five months (May to September 2018) in accordance with the European Commission Directive 2010/63/EU. The experiment was conducted under less intense farm conditions (low stocking density); hence, the ethics committee's approval was not required. It is not required for services that do not cause pain, suffering, distress, or permanent damage to the body of animals. The experiment involved 12 litters, with 117 piglets (Swedish Landrace $\times$ Large White). Details about the pre-weaning housing and care of animals are described in Mesarec et al. [6]. At weaning, piglets were housed in an experimental room divided by $100 \mathrm{~cm}$ high solid plastic walls into three equal pens $(2.0 \mathrm{~m} \times 2.3 \mathrm{~m})$ with no access to an outdoor area (Figure 1). The average room temperature was maintained at $26^{\circ} \mathrm{C}$, regulated by a ventilation panel. Each pen was additionally equipped with a heating panel. The pens had a metal slatted floor covered with perforated plastic material. The pens were connected by narrow passages, $20 \mathrm{~cm}$ wide and $30 \mathrm{~cm}$ high, through which only one piglet could pass at a time; the passages could optionally be closed. A combination of daylight entering through the windows and artificial light was used to guarantee $14 \mathrm{~h}$ of light (minimum $40 \mathrm{~lx}$ ) and $10 \mathrm{~h}$ of darkness per day. The piglets were fed ad libitum with a commercial balanced creep feed mixture for weaned piglets, with free access to water. Each pen was equipped with a feeding trough and two nipple drinkers.

A
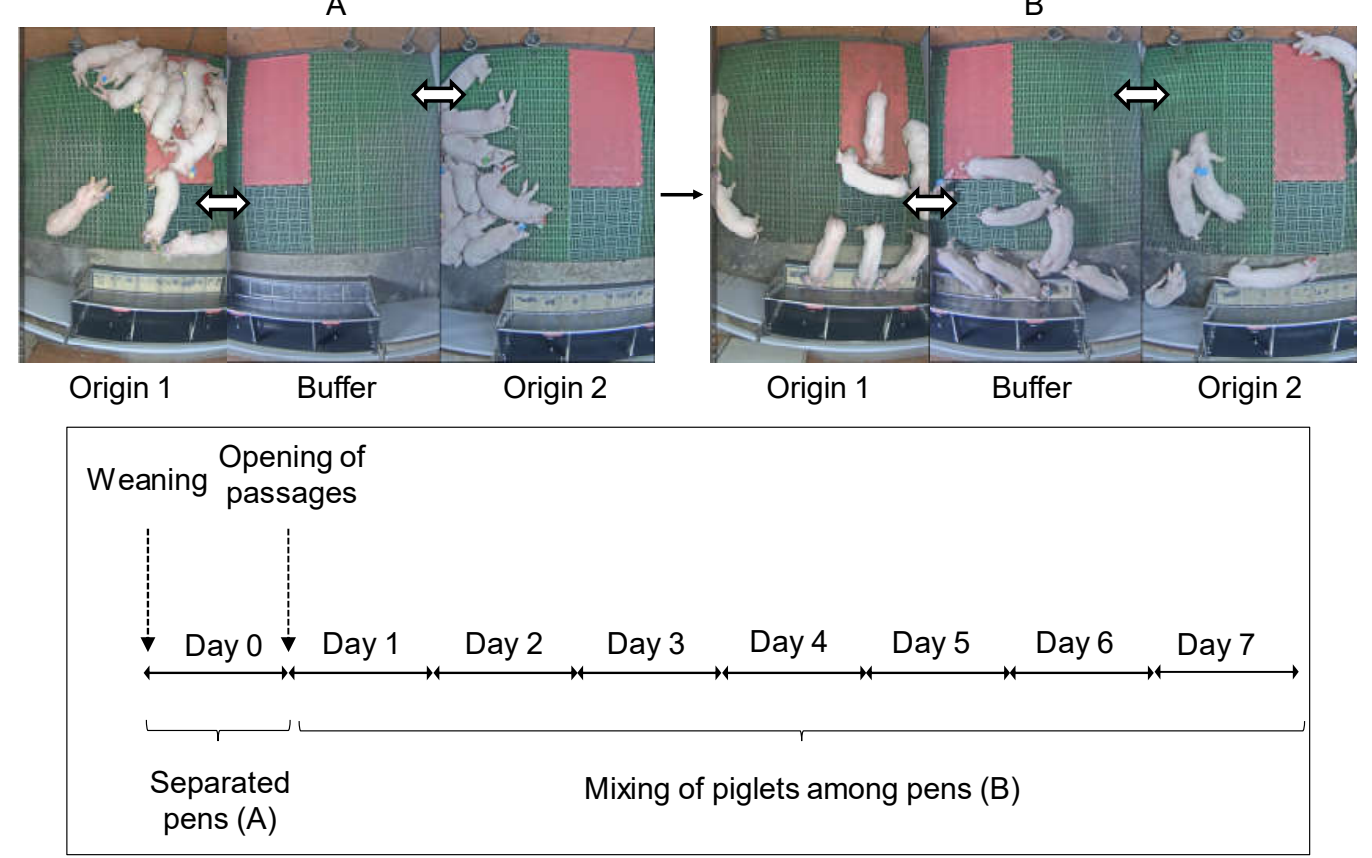

Figure 1. Experimental design. $\Leftrightarrow$ —passage, (A)—before mixing, (B)—after mixing. 


\subsection{Experimental Design}

The experiment was conducted in six repetitions, using different litters of similar age each time. Litter characteristics are given in Table 1. On the day of weaning (day 0), the piglets were individually weighed and marked with plastic ear tags of different colours, in distinct colour combinations (four different colours, marking in one or both ears). The two litters were then placed in two separate pens, designated as origin 1 and origin 2 (Figure 1A). On day 0 , the intermediate pen (buffer) remained empty. The passages remained closed for $24 \mathrm{~h}$, allowing the animals to habituate to the new physical environment. On day 1 , the passages to the buffer were opened, allowing spontaneous mixing of the groups (Figure 1B). The experiment lasted 7 days after the passages were opened. At the end of the experiment, the animals were individually weighed again.

Table 1. Basic litter/piglet characteristics for all six repetitions.

\begin{tabular}{cccc}
\hline Repetition & $\begin{array}{c}\text { n of Pigs } \\
\text { (Male/Female) }\end{array}$ & $\begin{array}{c}\text { Age at } \\
\text { Weaning, Days }\end{array}$ & $\begin{array}{c}\text { Body Weight } \\
\text { at Weaning, kg }\end{array}$ \\
\hline 1 & $19(14 / 5)$ & 36 & $9.2 \pm 1.5$ \\
2 & $19(9 / 10)$ & 32 & $10.7 \pm 1.6$ \\
3 & $17(5 / 12)$ & 29 & $9.2 \pm 1.2$ \\
4 & $21(11 / 10)$ & 37 & $12 \pm 1.7$ \\
5 & $17(7 / 10)$ & 35 & $11.4 \pm 1.5$ \\
6 & $24(13 / 11)$ & 31 & $8.3 \pm 1.8$ \\
\hline All & $117(59 / 58)$ & 33.5 & $10.2 \pm 2.1$ \\
\hline
\end{tabular}

The experiment was designed in such a way as to allow piglets to mix spontaneously (not abruptly as in the standard weaning procedure), and in addition, to make tracking individual animals easier. However, it can also represent an alternative method of weaning.

\subsection{Recording of Behavioural Data and Observations}

All three pens were equipped with a video system, with one Axis P1425-LE HD camera (Axis Communications AB, Lund, Sweden) attached to the ceiling in the central position to cover the entire area of the pen. The experiment was continuously filmed. For each observation day, the most active period of the day from 8:00 (after feeding) to 13:00 was analysed from the video recordings. Two types of interactions were monitored:

fighting: the piglets were in constant social contact with each other, shoving, pushing, biting, and head-knocking; both piglets were trying to hurt each other;

mounting: one piglet was standing on his hind legs, while both front legs were over the back, rear, side, or head of another piglet.

For each event, the following parameters were collected: day, location (pen), identities of the participating piglets and their respective roles (initiator or responder), and interaction type. For fighting, the outcome (win/lose/draw) was also recorded:

winner: the piglet that did not retreat from the fight, the one that sought for retaliation; loser: the piglet that first retreated from the fight without retaliation; draw fight: the piglets started a fight, but then both suddenly stopped and moved away; win/lose: outcome of fight for the initiator (win — the initiator won, lose-the initiator lost).

\subsection{Statistical Analysis}

Observational data were combined with information on the original litter of piglets that participated in a fight or a mount. For each interaction, type was defined based on the original litter (designated origin 1 and origin 2) of the animals involved in the activity: within-litter (from either origin 1 or origin 2) and between-litter. Territory was also defined based on the original litter of piglets and the location of the fight/mount: home (the pen where a piglet's litter was weaned), neutral (buffer pen), and foreign (the pen where another 
litter was weaned). To analyse the asymmetry in body weight, the difference between the body weight of the initiator and the responder was also calculated.

Statistical analyses were carried out using SPSS software, version 25.

1. The temporal dynamics of within-litter interactions was analysed using frequency analysis. The actual and relative frequencies of within-litter fights/mounts were calculated for each observation day and for the entire observation period.

2. The territorial distribution of within-litter interactions was analysed using a generalised linear model (GENLIN procedure). For this analysis, the original data were pooled by observation day and territory separately for within-litter and between-litter interactions. The response variable obtained (count data) was analysed on a pen level using the GENLIN model with a negative binomial distribution to model the count data (with log link). Predictor variables were observation day (1-7), territory (home, neutral, and foreign), and their interactions. Repetition was included in the model as a random variable. Estimated means with standard errors were calculated for fixed effects and interaction (by back-transforming model coefficients). Post hoc comparisons were adjusted using the Bonferroni correction for multiple testing.

3. To analyse the fight outcome in relation to the type of interaction, the frequencies for different fight outcomes (win/lose/draw) were calculated separately for within-litter and between-litter fights and tested with the $\chi^{2}$-test.

4. Body weight asymmetry in within- and between-litter interactions was analysed using a linear mixed (MIXED) model as a function of behaviour type (model 1) and the outcome of fights (model 2). Model 1 comprised the fixed effect of interaction type (within- and between-litter) and the random effect of repetition and was run separately for fighting and mounting. For fights only, model 2 was applied with the fixed effect of fight outcome (win, draw, and loss) and the random effect of repetition. Estimated means with standard errors were calculated for fixed effects. Post hoc comparisons were adjusted for multiple testing using the Bonferroni correction.

\section{Results}

\subsection{Temporal Dynamics of Within-Litter Interactions}

During the whole observation period, a total of 2792 fights and 1567 mounts were recorded, of which 1055 fights and 1068 mounts occurred between littermates. Therefore, contrary to the interactions between piglets from different litters, where fighting predominated over mounting (3.5:1 ratio), there was an almost perfect balance (1:1) between both interactions when the confronted piglets were from the same litter. The temporal dynamics of within-litter interactions (Figure 2) showed the highest daily increase in the frequency of fighting and mounting on day 1 , when the passages between pens were opened. The number of within-litter fights increased nearly 6 -fold compared to day 0 and remained at a similar level on day 2. Thereafter, it decreased over time and reached the initial (day 0 ) level at the end of the observation period, i.e., day 7 (Figure 2a). Similarly, the number of within-litter mounts increased 7-fold on day 1 compared to day 0 , but contrary to fighting, it continued to increase on the following days, except for the last two days (Figure 2b). Figure 2 also shows the percentage of within-litter fights and mounts by observation day. On average, within-litter interactions accounted for about one-third of all fights and about two-thirds of all mounts recorded throughout the observation period. Looking at the temporal distribution, within-litter fights accounted for about $40 \%$ of all fights in the first days and then gradually decreased to $28 \%$ (Figure 2a). Within-litter mounts accounted for $50 \%$ of all mounts immediately after mixing (day 1 ), but then increased considerably and prevailed on the next days (days 2 to 4 ), when approximately $80 \%$ of all mounts involved littermates. Thereafter, the proportion of within-litter mounts gradually decreased until it reached the initial level (50\% of all mounts) at the end of the observation period (Figure $2 b$ ). 

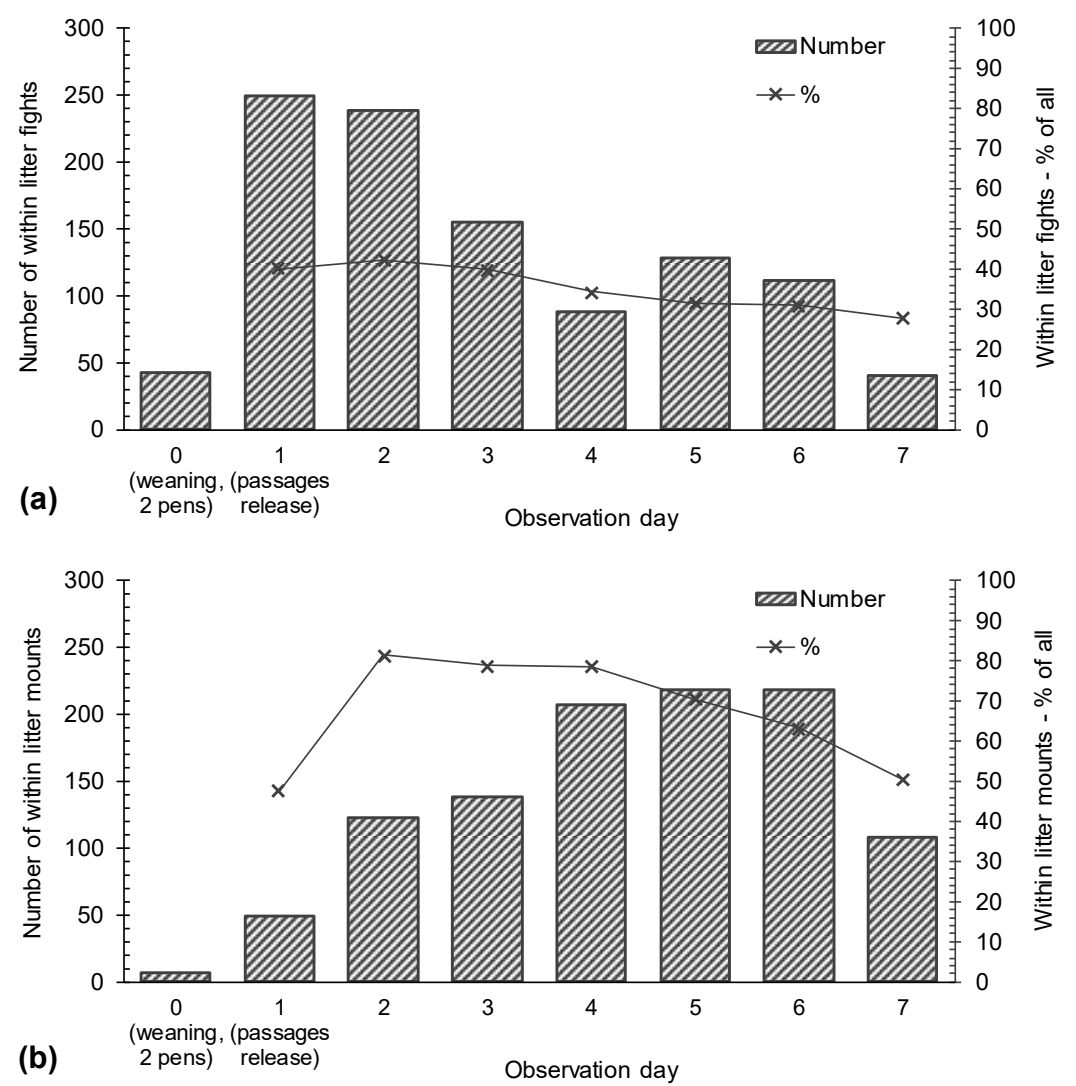

Figure 2. Temporal dynamics of within-litter interactions; (a) fighting, (b) mounting.

\subsection{Territoriality in Within-Litter Interactions}

In general, the major part of within-litter interactions $(\approx 50 \%)$ occurred in the home pens, followed by a buffer with about one-third of all interactions. Only a small proportion of within-litter fights/mounts occurred in foreign territory (Figure 3). However, the temporal distribution of within-litter interactions in different territories showed differences only in the first days after mixing with a significantly higher number of fights and mounts in the home territory (days 1, 2 and days 2, 3, respectively), followed by the buffer. Later, no significant difference in territorial distribution was observed. 

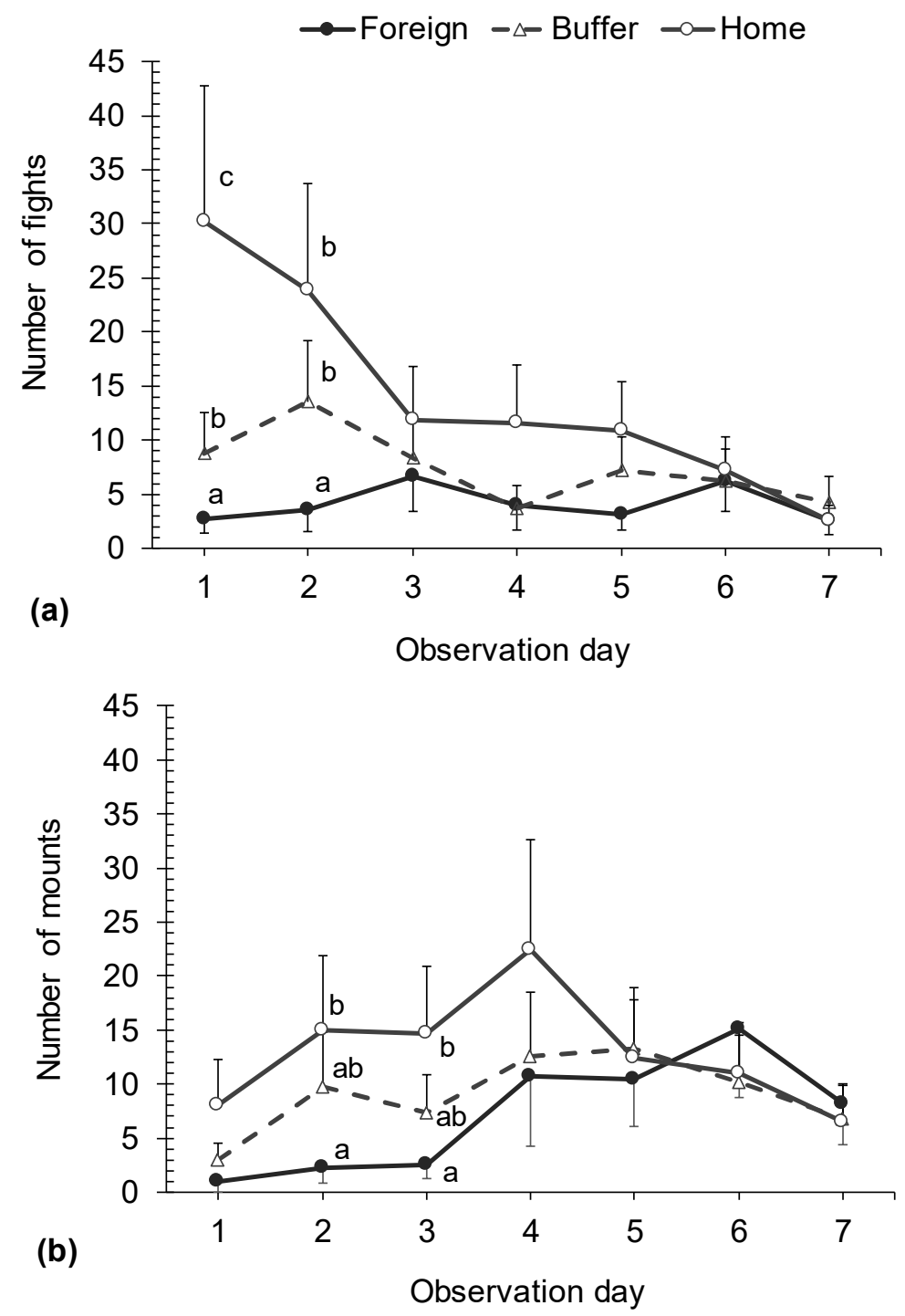

Figure 3. Distribution of within-litter interactions across territories by observation day; (a) fighting, (b) mounting. Values marked with different superscript letters differed significantly by $p<0.05$ (among territories within observation day).

\subsection{Outcome of Fights}

We obtained an interesting result regarding the outcome of fights (Figure 4). A similar percentage of wins and draws ( $50 \%$ and $42 \%$, respectively) was observed for within-litter fights. By contrast, the initiator won in as many as $80 \%$ of between-litter fights, and only $11 \%$ of the fights ended in a draw. There were no differences between the groups regarding the percentage of lost fights. 


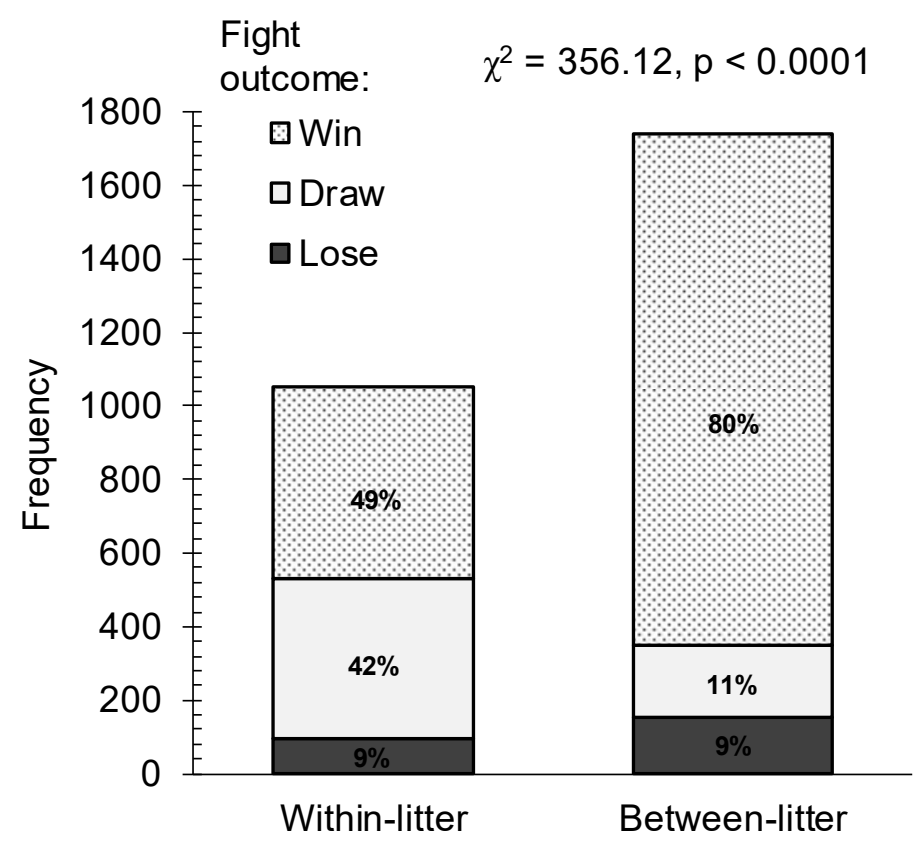

Figure 4. Outcome of fights-comparison of within- and between-litter interactions.

\subsection{Body Weight Asymmetry}

Figure 5 shows the results of the analysis of asymmetry of piglets in pairs (participants of fighting or mounting). In fighting, the initiator was generally heavier, whereas in mounting, he was generally lighter. These differences were more pronounced in betweenlitter interactions, although they were statistically significant only in the case of fighting (Figure 5a). The results also showed a pronounced asymmetry of body weight in relation to the outcome of fights. The initiator who won the fight was heavier (average difference of 0.4 to $0.6 \mathrm{~kg}$ ). Even in the case of a draw, somewhat heavier piglets initiated the fight (average difference of 0.1 to $0.3 \mathrm{~kg}$ ). The initiator who lost the fight had a lower body weight than his opponent, especially in within-litter fights (by 0.8 and $0.2 \mathrm{~kg}$ in within- and between-litter fights, respectively).

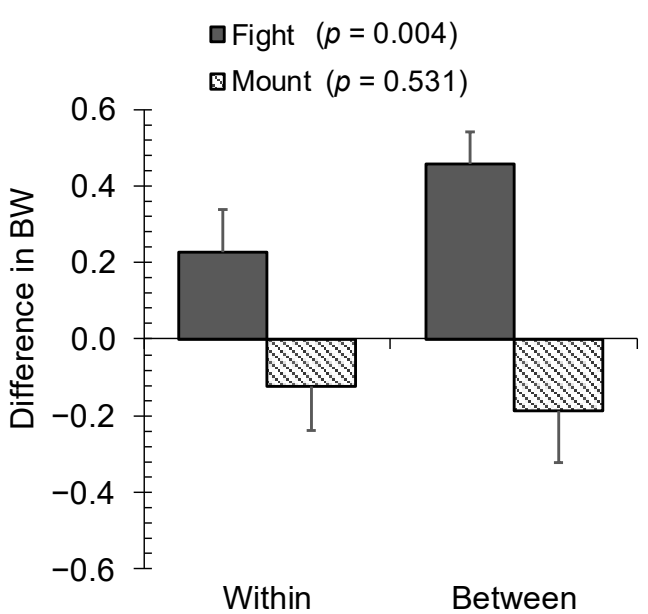

(a)

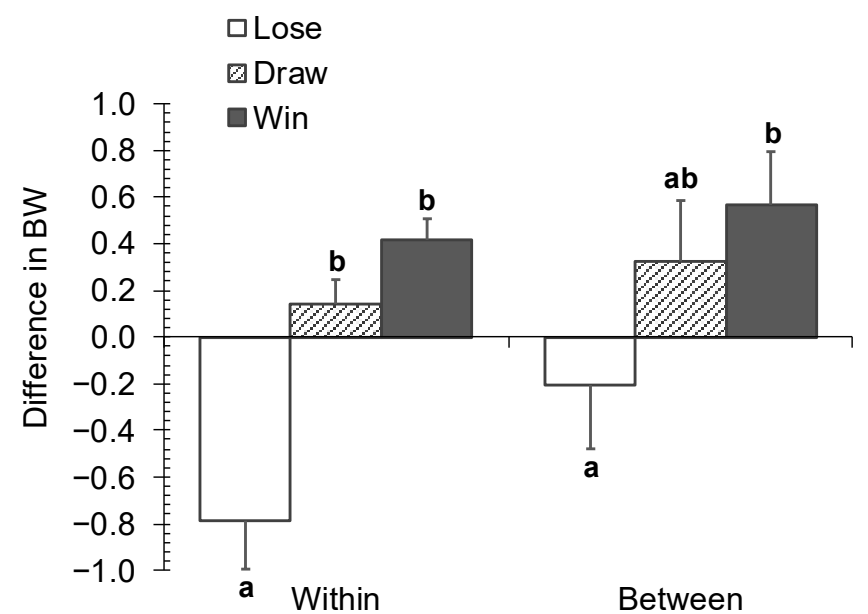

(b)

Type of fight

Figure 5. Body weight asymmetry in within- and between-litter interactions in relation to (a) behaviour type (fighting, mounting) and (b) outcome of fight (win, draw, lose); BW-body weight. Values marked with different superscript letters differed significantly by $p<0.05$ (among outcomes within type of fight). 


\section{Discussion}

In the present study, we confirmed that within-litter interactions, both fighting and mounting, increased significantly during the first two days after litters were spontaneously combined into a single weaning group and gradually decreased thereafter. Furthermore, we confirmed that within-litter interactions, both fighting and mounting, occurred predominantly in the home pen where the litter was weaned to. The initiator of within-litter fights mostly won, but the proportion of drawn fights was equal to the proportion of won fights, and significantly higher than the proportion of drawn fights between unacquainted piglets (non-littermates). Results also confirmed lower body weight asymmetry (RHP) in the piglets involved in within-litter interactions.

Within-litter agonism outbursts already immediately after birth, when the piglets spontaneously establish their first social order, which manifests as a suckling order/fidelity $[7,8]$. The suckling order is considered to be fully established about 1 week after birth, with the most pronounced agonism between littermates noted in the first two days after birth $[7,8]$; later, agonism decreases steadily. According to our results, mixing with another litter at weaning seems not only to trigger the process of forming a social order between unacquainted litters, but also to reactivate it within each litter. In our study, namely, fighting between littermates increased 6-fold in the first two days after mixing, compared with the rather rare occurrence of fighting on the first day of weaning, when litters were still in their own (home) weaning pens, separated from each other and thus unable to mix with unfamiliar individuals. Thereafter, the within-litter fighting steadily decreased, but this is a temporal pattern already known in the context of the formation of a new social order, either during lactation or through the establishing of a new weaning group. Although fighting is a normal concomitant phenomenon of the mixing of unacquainted animals [4], it is often intuitively attributed to conflicts between unfamiliar individuals from different litters, while conflicts between littermates are often completely neglected in this context. Yet, our results showed that during the first two days, when fighting was most intense, more than $40 \%$ of all weaning fights occurred between littermates, despite a well-established social order prior to litter mixing - as also indicated by the low rate of weaning fights prior to mixing. However, the within-litter fights showed some peculiarities not observed in the fights between unacquainted piglets (i.e., between-litter interactions). First, as the initiator of the between-litter fight is also a winner in a great majority of fights, the initiator of the within-litter fight had roughly equal chances of winning or drawing, while the chances of losing were small and comparable to those of between-litter fights. The explanation of this phenomenon is not trivial since several factors, such as previous experiences and resource holding capacity (RHP — body weight often as its indirect measure, and a measure of the social rank as well, see, e.g., [9]), influence the course of the contest.

Piglets engaged in the within-litter fights had previous mutual experiences which are of crucial importance in the context of fight [10,11], especially the winner/loser effect that is one of the most influential phenomena in the context of fight escalation [12]. According to the post-mixing rise of within-litter fights, as found in our study, it can be suggested that mixing with unacquainted piglets somehow disturbed the experience-based decisionmaking process in the piglets, causing littermates to resume mutual contests.

RHP, on the other hand, might be even more crucial, as it plays a role in the escalation of the fight, whereby between individuals with high RPH asymmetry, fights often do not escalate at all [11], as well as in the later stages of a contest. Namely, when the fight is already escalating, RHP influences the duration and outcome of a fight, with low asymmetry in RHP normally leading to longer and more intense fights with uncertain outcomes [11,13]. A high proportion of draws in our study suggests that littermates involved in each other's fights after weaning had similar RHP, as indirectly estimated by body weight asymmetry. Our results confirmed a lower asymmetry in the body weight of the opponents in within-litter fights, with the lowest differences in body weight found in fights that ended in a draw. 
A specific characteristic of post-mixing within-litter interactions is also reflected by mounting, an interaction that occurs in pigs of both sexes in various behavioural contexts (see, e.g., [14-16]), but can also be dominance-determining behaviour [17]. Although the ultimate role of mounting in dominance hierarchy formation has not yet been completely clarified (see [18]), it has recently been suggested to play an important role when the relative strengths of group members are known from previous confrontations and, as such, serves as a means of mutually determining strength to avoid fighting [6]. Our results on the post-mixing dynamics of within-litter mountings support this and showed a 7-fold rise in mounting on the first day of mixing, which is comparable to the increasing incidence of within-litter fighting. However, contrary to fighting, the frequency of within-litter mounting increased continuously almost throughout the observation period, rising 30 -fold and accounting for $80 \%$ of all mounts after weaning. Thus, mounting was found to be the most important interaction between individuals that had previously established a social order among themselves, while unknown individuals (between-litter interactions) still predominantly fought for position in the social order. Normally, piglets with higher social rank within their own litter tended to attack more than piglets with a lower rank and fought more aggressively against non-littermates [19].

Both within-litter interactions occurred at the highest rate in the home pen and decreased with distance, implying that the closer the piglet came to the foreign pen, the greater the chance and realisation of confrontation with an unknown piglet. The general territorial tendencies in within-litter interactions have already been reported by Mesarec et al. [6]; however, here we additionally showed that this type of territoriality decreased with time, and that was the case only in the first two (fighting) or three days (mounting) after piglets were allowed to mix spontaneously. Ultimately, maintaining an identical litter structure at weaning with unenforced mixing of litters, but with the possibility of spontaneous interactions between familiar and unfamiliar piglets in the buffer, is a rearing technology that could have a positive effect on piglet welfare. Furthermore, our results are consistent with previous research, which found that the presence of familiar individuals has a more pronounced buffering effect that influences well-being and the ability to cope with stress [20]. Therefore, mutual acquaintance of non-littermates before weaning can be of great importance to overcome excessive agonism at weaning even between littermates, which compromise pig welfare and growth performance all the way to the late phases of growth, e.g., by finishing pigs [21]. This can be effectively done by using one of several methods of early pre-weaning socialisation of piglets/litters that are intended to be combined at weaning; these methods, which differ either in number of litters allowed to mix during lactation, time of the lactation when socialisation is launched or whether only piglets or also the sows are allowed to mix during lactation, have recently been extensively studied and have been shown to be effective in reducing post-weaning aggression (see, e.g., [22-25]).

\section{Conclusions}

In conclusion, within-litter weaning agonism is mostly overlooked in the scientific literature, although its occurrence at weaning is far from negligible, as demonstrated in the present study. Therefore, the agonistic behaviour that normally escalates when a weaning group is formed by joining two or more litters is not only due to the formation of a new social order among unacquainted individuals, but also due to the agonistic interactions between littermates that apparently recur because of mixing at weaning. By quantifying the outcome of antagonism in the relationships between piglets, both within- and betweenlitter, we obtain important information about the potential social dynamics in the group and its formation, which could help us to predict the occurrence of different behavioural patterns in piglets after weaning. Consequently, we could adapt husbandry conditions and management and improve the health and welfare of weaned piglets. 
Author Contributions: Conceptualisation, J.S.; data curation, M.P.P.; formal analysis, M.P.P. and N.M.; funding acquisition, D.Š.; investigation, N.M. and J.S.; methodology, N.M. and J.S.; project administration, D.Š.; resources, D.Š.; software, M.P.P.; supervision, M.P.P.; validation, M.P.P. and J.S.; visualisation, M.P.P.; writing—original draft, M.P.P. and J.S.; writing—review and editing, M.P.P., J.S. and D.Š. All authors have read and agreed to the published version of the manuscript.

Funding: This research was funded by the Slovenian Research Agency, grant number P1-0164.

Institutional Review Board Statement: Ethical review and approval were waived for this study, as the experiment was conducted under less intense farm conditions (low stocking density) that did not cause pain, suffering, distress, or permanent damage to the body of animals.

Informed Consent Statement: Not applicable.

Data Availability Statement: Not applicable.

Conflicts of Interest: The authors declare no conflict of interest.

\section{References}

1. Bøe, K. The process of weaning in pigs: When the sow decides. Appl. Anim. Behav. Sci. 1991, 30, 47-59. [CrossRef]

2. $\quad$ Pluske, J.R.; Le Dividich, J.; Verstegen, M.W. (Eds.) Weaning the Pig: Concepts and Consequences; Wageningen Academic Publishers: Wageningen, The Netherlands, 2003; 432p.

3. Rosillon-Warnier, A.; Paquay, R. Development and consequences of teat-order in piglets. Appl. Anim. Behav. Sci. 1984, 13, 47-58. [CrossRef]

4. Meese, G.B.; Ewbank, R. The establishment and nature of the dominance hierarchy in the domesticated pig. Anim. Behav. 1973, 21, 326-334. [CrossRef]

5. Skok, J.; Prevolnik, M.; Urek, T.; Mesarec, N.; Škorjanc, D. Behavioural patterns established during suckling reappear when piglets are forced to form a new dominance hierarchy. Appl. Anim. Behav. Sci. 2014, 161, 42-50. [CrossRef]

6. Mesarec, N.; Skok, J.; Škorjanc, D.; Prevolnik Povše, M. Group dynamics in a spontaneously established group of newly weaned piglets. Appl. Anim. Behav. Sci. 2021, 238, 105317. [CrossRef]

7. De Passille, A.M.B.; Rushen, J.; Hartsock, T.G. Ontogeny of teat fidelity in pigs and its relation to competition at suckling. Can. J. Anim. Sci. 1988, 68, 325-338. [CrossRef]

8. De Passille, A.M.B.; Rushen, J. Suckling and teat disputes by neonatal piglets. Appl. Anim. Behav. Sci. 1989, 22, 23-38. [CrossRef]

9. Erhard, H.W.; Mendl, M. Measuring aggressiveness in growing pigs in a resident-intruder situation. Appl. Anim. Behav. Sci. 1997, 54, 123-136. [CrossRef]

10. Rushen, J. Assessment of fighting ability or simple habituation: What causes young pigs (Sus scrofa) to stop fighting? Aggress. Behav. 1988, 14, 155-167. [CrossRef]

11. Camerlink, I.; Turner, S.P.; Farish, M.; Arnott, G. The influence of experience on contest assessment strategies. Sci. Rep. 2017, 7, 14492. [CrossRef]

12. Oldham, L.; Camerlink, I.; Arnott, G.; Doeschl-Wilson, A.; Farish, M.; Turner, S.P. Winner-loser effects overrule aggressiveness during the early stages of contests between pigs. Sci. Rep. 2020, 10, 13338. [CrossRef] [PubMed]

13. Andersen, I.L.; Andenæs, H.; Bøe, K.E.; Jensen, P.; Bakken, M. The effects of weight asymmetry and resource distribution on aggression in groups of unacquainted pigs. Appl. Anim. Behav. Sci. 2000, 68, 107-120. [CrossRef]

14. Fraser, D. The behaviour of growing pigs during experimental social encounters. J. Agric. Sci. 1974, 82, 147-163. [CrossRef]

15. Rydhmer, L.; Zamaratskaia, G.; Andersson, H.K.; Algers, B.; Lundström, K. Problems with aggressive and sexual behaviour when rearing entire male pigs. In Proceedings of the 55th Annual Meeting of the European Association for Animal Production, Bled, Slovenia, 5-9 September 2004; p. 4.

16. Clark, C.C.; D'Eath, R.B. Age over experience: Consistency of aggression and mounting behaviour in male and female pigs. Appl. Anim. Behav. Sci. 2004, 147, 81-93. [CrossRef]

17. Hintze, S.; Scott, D.; Turner, S.; Meddle, S.L.; D'Eath, R.B. Mounting behaviour in finishing pigs: Stable individual differences are not due to dominance or stage of sexual development. Appl. Anim. Behav. Sci. 2013, 147, 69-80. [CrossRef]

18. Fredriksen, B.; Lium, B.M.; Marka, C.H.; Mosveen, B.; Nafstad, O. Entire male pigs in farrow-to-finish pens-Effects on animal welfare. Appl. Anim. Behav. Sci. 2008, 110, 258-268. [CrossRef]

19. Fels, M.; Hoy, S.; Hartung, J. Influence of origin litter on social rank, agonistic behaviour and growth performance of piglets after weaning. Appl. Anim. Behav. Sci. 2012, 139, 225-232. [CrossRef]

20. Kanitz, E.; Hameister, T.; Tuchscherer, M.; Tuchscherer, A.; Puppe, B. Social support attenuates the adverse consequences of social deprivation stress domestic piglets. Horm. Behav. 2014, 65, 203-210. [CrossRef]

21. Camerlink, I.; Bijma, P.; Kemp, B.; Bolhuis, J.E. Relationship between growth rate and oral manipulation, social nosing, and aggression in finishing pigs. Appl. Anim. Behav. Sci. 2012, 142, 11-17. [CrossRef]

22. D'Eath, R.B. Socialising piglets before weaning improves social hierarchy formation when pigs are mixed post-weaning. Appl. Anim. Behav. Sci. 2005, 93, 199-211. [CrossRef] 
23. Verdon, M.; Morrison, R.S.; Hemsworth, P.H. Rearing piglets in multi-litter group lactation systems: Effects on piglet aggression and injuries post-weaning. Appl. Anim. Behav. Sci. 2016, 183, 35-41. [CrossRef]

24. Salazar, L.C.; Ko, H.L.; Yang, C.H.; Llonch, L.; Manteca, X.; Camerlink, I.; Llonch, P. Early socialisation as a strategy to increase piglets' social skills in intensive farming conditions. Appl. Anim. Behav. Sci. 2018, 206, 25-31. [CrossRef]

25. Mesarec, N.; Pačnik, U.; Mesarič, A.; Skok, J.; Škorjanc, D.; Zupan, M.; Prevolnik Povše, M. The effect of socialising piglets during lactation on performance, suckling behaviour and weaning aggression: A preliminary field study. Acta Univ. Agric. Silvic. Mendel. Brun. 2020, 68, 73-79. [CrossRef] 